\title{
PERANCANGAN DAN PEMBUATAN MESIN PEMOTONG PADI SEDERHANA DI DESA PITALAH KABUPATEN TANAH DATAR
}

\author{
Oknovia Susanti*) $^{*}$ dan Bima Sugesti Arif \\ Jurusan Teknik Mesin Fakultas Teknik Universitas Andalas \\ *) Email: Oknovia.s@gmail.com
}

\begin{abstract}
ABSTRAK
Kegiatan ini membahas tentang perancangan dan pembuatan mesin pemotong padi sederhana, adapun manfaatnya berguna untuk membantu para petani saat proses pengerjaan pemanenan yang selama ini menggunakan sabit sebagai alat pemotong padi tradisional. Mesin pemotong padi sederhana terdiri dari beberapa komponen yaitu rangka utama, mata pisau potong $40 \mathrm{~T}$, pelempar padi, mesin potong rumput Yasui YSI-328, dan roda. Perancangan untuk rangka utama memakai besi Galvanis dengan ukuran 1 inch, spesifikasi mesin pemotong rumput Yasui YSI-328 termasuk kategori mesin 2 Tak dengan kemampuan $1.8 \mathrm{HP} 7000 \mathrm{rpm}$, diameter mata pisau potong $40 \mathrm{~T}$ yaitu $255 \mathrm{~mm}$, komponen pelempar padi berguna untuk menata padi agar rebah ke samping setelah pemotongan bertujuan agar padi tidak terinjak oleh alat dan komponen selanjutnya, untuk memudahkan alat berjalan di sawah memakai roda Artco. Aplikasi pendukung dalam pembuatan design bentuk produk memakai software Solidworks 2014 sehingga diperoleh gambar dari produk tersebut. Untuk proses fabrikasi dilakukan di bengkel sampai alat siap dalam bentuk yang sesuai dengan design pada gambar. Setelah alat selesai selanjutnya ialah tahap pengujian. Tahap pengujian dilakukan di lahan sawah. Parameter yang akan diamati adalah kapasitas kerja saat dilakukan pemotongan terhadap variasi rpm dan konsumsi bahan bakar Nilai rata-rata kapasitas kerja mesin pemotong padi sederhana saat percobaan adalah 0,0131 ha/jam; 0,0141 ha/jam; 0,0149 ha/jam pada masing-masing variasi rpm mesin yaitu $1900 \mathrm{rpm}, 3700 \mathrm{rpm}$ dan $5000 \mathrm{rpm}$. Sedangkan ratarata kapasitas kerja menggunakan sabit tradisional adalah 0,0105 ha/jam. Konsumsi bahan bakar yang habis pada variasi $1900 \mathrm{rpm}, 3700 \mathrm{rpm}$ dan $5000 \mathrm{rpm}$ masing masing adalah 15,3333 1/ha; 14 1/ha dan 12,6667 1/ha.
\end{abstract}

Kata Kunci: mesin pemotong padi, galvanis, yasui YSI-328, roda artco, solidwork 2014,kapasitas kerja mesin, konsumsi bahan bakar.

\section{Design and Manufacture of Simple Rice Cutting Machines}

\begin{abstract}
This activities discusses the design and manufacture of a simple rice cutting machine, while its benefits are useful for helping farmers during the harvesting process who have been using sickles as traditional rice cutting tools. A simple rice mower consists of several components, namely the main frame, a 40T blade, a thrower, Yasui YSI-328 lawn mower, and wheels. The design for the main frame uses Galvanized iron with a size of 1 inch, the specification of the Yasui YSI-328 lawn mower is a 2-stroke engine with a capacity of $1.8 \mathrm{HP} 7000 \mathrm{rpm}$, a blade diameter of $40 \mathrm{~T}$ is $255 \mathrm{~mm}$, a rice thrower component is useful for arranging rice so that lying sideways after cutting aims to prevent the rice from being stepped on by the next tools and components, to make it easier for the tools to walk under the Artco wheel. Supporting applications in making product design using Solidworks 2014 software so that an image of the product is obtained. The fabrication process is carried out in the workshop until the tool is ready in a form that matches the design in the image. After the tool is complete, the next step is the testing phase. The testing phase is carried out in the rice field. The parameters to be observed are the working capacity when cutting the variation of rpm and fuel consumption. The average value of the working capacity of a simple rice cutting machine during the experiment is 0.0131 ha / hour; 0.0141 ha / hour; 0.0149 ha / hour at each variation of engine rpm, namely $1900 \mathrm{rpm}, 3700 \mathrm{rpm}$ and $5000 \mathrm{rpm}$. While the average working capacity using traditional sickles is 0.0105 ha / hour. The exhausted fuel consumption at variations of $1900 \mathrm{rpm}, 3700 \mathrm{rpm}$ and $5000 \mathrm{rpm}$ respectively is $15.33331 /$ ha; $141 /$ ha and $12.66671 /$ ha.
\end{abstract}

Keywords: rice cutting machine, galvanized, yasui YSI-328, artco wheel, solidwork 2014, machine work capacity, fuel consumption. 


\section{PENDAHULUAN}

Pada saat ini proses pemanenan padi telah beralih dari cara tradisional ke pemanenan secara modern yang mulai diterapkan pada zaman sekarang. Namun kegiatan pemanenan di sebagian daerah pelosok umumnya belum mengenal dan memahami pemanenan padi secara modern, masyarakat di sana yang berprofesi sebagai petani masih memilih cara tradisional dalam penanganannya. Penggunaan sabit sebagai alat panen tradisional menjadi salah satu penyebab kehilangan hasil panen hingga kurang lebih $10 \%$ (9,52\%) (Iswari 2012). Selain kurangnya tenaga pemanen, kelelahan saat panen berdampak terhadap hasil panen. Pemanenan tradisional untuk suatu wilayah dengan areal sawah yang luas dibutuhkan tenaga pemanen dalam jumlah besar. Kelemahan pada alat tradisional yaitu bergantung kepada fisik si petani karena memengaruhi tingkat kinerja seorang petani jika dilakukan dalam kurun waktu yang cukup lama dan kecepatan dalam pemotongan tidak bisa dilakukan secara cepat bila dibandingkan dengan mesin pemanen modern(Yanti et al. 2020).

Mesin pemanen modern saat sekarang ini seperti mesin mower, reaper, mini combine ataupun combine harvester dapat menjadi alternatif untuk menggantikan cara tradisional namun harga yang begitu mahal dipasaran dan umumnya yang memiliki masih relatif sedikit. Berdasarkan permasalahan tersebut penulis merancang alat pemotong padi dengan harga terjangkau bagi petani, dengan mengutamakan kenyaman dan kehandalan alat tersebut dibandingkan dengan alat tradisional. Sehingga dilakukanlah kegiatan berjudul "Perancangan dan Pembuatan Mesin Pemotong Padi Sederhana". Harapannya alat ini dapat menggantikan alat tradisional agar membantu petani ketika saat pemanenan.

\section{METODE}

\section{Proses Pembuatan}

Proses pembuatan mesin pemotong padi sederhana melalui langkah- langkah sebagai berikut :

a. Membaca gambar hasil rancangan yang telah di desain

b. Mengukur dimensi bahan yang akan dipotong dengan meteran

c. Proses Pemotongan bahan menggunakan gerinda potong

d. Proses Pengelasan dalam pembuatan rangka

e. Proses pemasangan roda pada rangka

f. Proses pemasangan mesin rumput yasui ysi-328 pada rangka

g. Proses pemasangan mata pisau potong $40 \mathrm{~T}$

h. Proses pemasangan pelempar padi

\section{Rancangan Fungsional}

Rancangan fungsional ini dilakukan untuk menentukan fungsi dan komponen alat penyiangan pada tanaman padi.

a. Rangka Utama

Rangka Utama merupakan kerangka dasar tempat bertumpunya semua komponen-komponen alat.

b. Mata Pisau Potong $40 \mathrm{~T}$ 
Pisau pemotong sudah terbuat dari standar pabrik, berfungsi untuk memotong padi.

c. Pelempar Padi

Berguna untuk mengarahkan posisi padi ke arah samping saat dilakukan pemotongan.

d. Mesin Potong Rumput Yasui YSI-328

Mesin ini berguna untuk sebagai sumber tenaga untuk memutar mata pisau potong $40 \mathrm{~T}$ yang digunakan untuk proses pemotongan padi.

e. Roda

Roda menggunakan produk standard dari roda gerobak artco berfungi untuk membantu agar alat dapat berjalan di area sawah.

\section{Persiapan Sebelum Pengujian Alat}

a. Mesin Pemotong padi

b. Mesin diukur rpmnya menggunakan tachometer, kemudian ditandai pada tuas gas untuk menjaga konsistensi kecepatan. RPM yang digunakan yaitu 1900, 3700, dan 5000. Selanjutnya, pengukuran volume tangki dilakukan untuk mengetahui konsumsi bahan bakar yang dibutuhkan, untuk alat ukurnya menggunakan gelas ukur.

c. Pengukuran Lintasan Lahan

d. Lintasan lahan yang digunakan untuk penelitian ini yaitu membagi luasan sawah yang akan dipanen masing-masing menjadi 1 rumpun padi dengan panjang lintasan $10 \mathrm{~m}$ diukur menggunakan meteran kemudian dibatasi menggunakan tali rafia.

\section{Proses Pemanenan}

Mesin pemotong padi dioperasikan pada proses pemanenan dengan cara mengelilingi sawah. Sampel pengujian diambil dengan variasi 3 tingkatan RPM yang sudah ditentukan, untuk satu tingkat RPM dilakukan pengulangan sebanyak 40 kali. Setelah selesai pemanenan, dilakukan pengumpulan dan pelepasan kantong plastik dari malai padi, dapat dilihat pada Gambar 1.

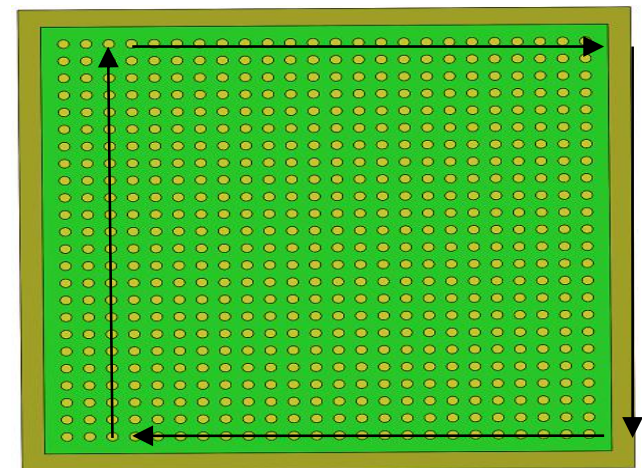

Gambar 1. Plot Percobaan Panjang Lintasan 10 m Dengan 3 Tingkatan RPM

\section{Bahan dan Alat}

Bahan yang digunakan dalam penelitian ini adalah mesin pemotong rumput Yasui YSI-328, roda artco, mata pisau potong $40 \mathrm{~T}$, besi galvanis 1 inch, besi siku $40 \times 40 \times 4 \mathrm{~mm}$, besi beton $12 \mathrm{~mm}$, seng plat, besi strip, mor dan baut. Adapun beberapa 
alat yang digunakan adalah las listrik, gerinda, ragum, bor dan kunci-kunci perkakas bengkel. Alat ukur yang digunakan dalam penelitian ini adalah digital tachometer, neraca pegas, gelas ukur, meteran, busur dan sotpwatch.

\section{Bahan Pembuatan Mesin Pemotong Padi}

1. Mesin Yasui YSI-328

Digunakan untuk sebagai sumber tenaga untuk menggerakkan mata pisau potong.

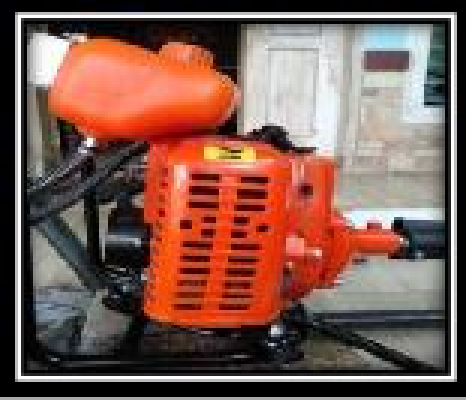

Gambar 2. Mesin Yasui YSI-328

2. Roda Artco

Digunakan untuk tumpuan rangka dan bagian yang langsung berkontak dengan lintasan sawah.

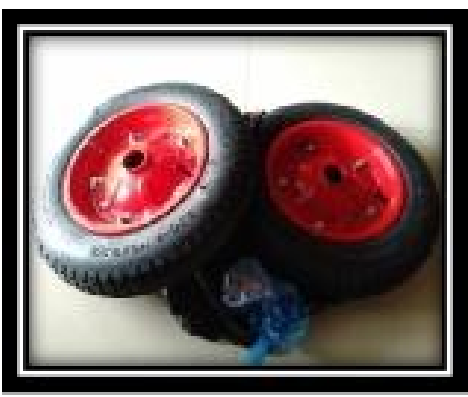

Gambar 3. Roda Artco

3. Mata Pisau Potong $40 \mathrm{~T}$

Digunakan untuk memotong rumpun padi

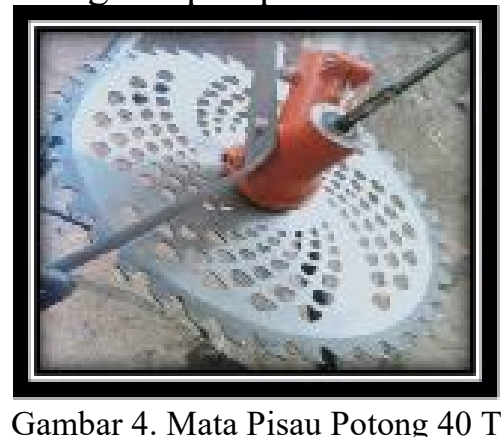

4. Besi Galvanis 1 inch

Digunakan untuk sebagai bahan utama pembuatan rangka 


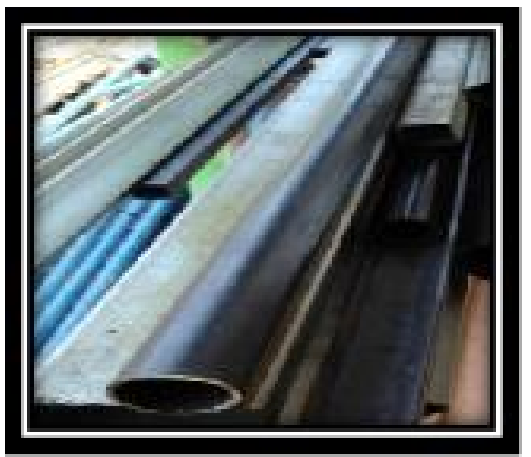

Gambar 5. Besi Galvanis 1 inch

5. Besi Siku $40 \times 40 \times 4 \mathrm{~mm}$

Digunakan untuk bahan pendukung konstruksi rangka

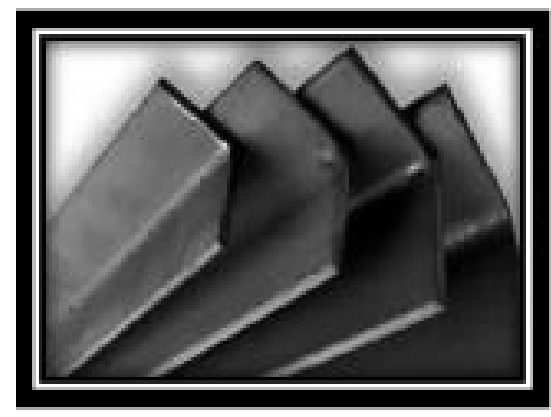

Gambar 6. Besi Siku 40x40x4 mm

6. Besi Beton $12 \mathrm{~mm}$

Digunakan sebagai bahan pendukung konstruksi rangka

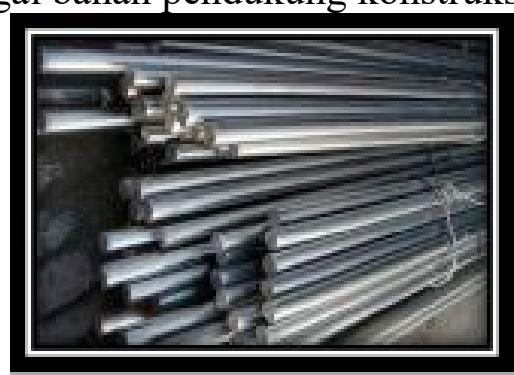

Gambar 7. Besi Beton 12 mm

7. Seng Plat

Digunakan untuk membuat pelempar padi

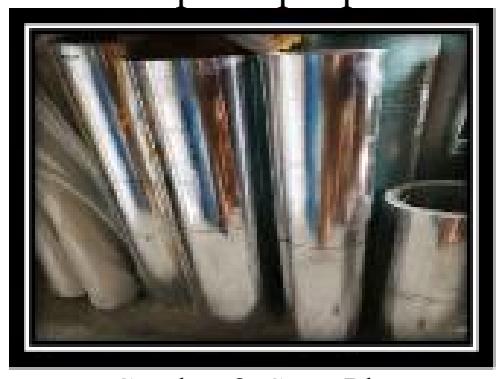

Gambar 8. Seng Plat 


\section{Besi Strip}

Digunakan sebagai bahan pendukung rangka dan bagian penangkap

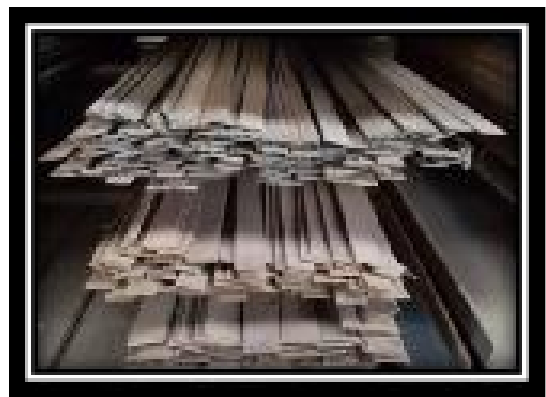

Gambar 9. Besi Strip

9. Mor dan Baut

Digunakan untuk menyambung antar komponen yang akan dirakit

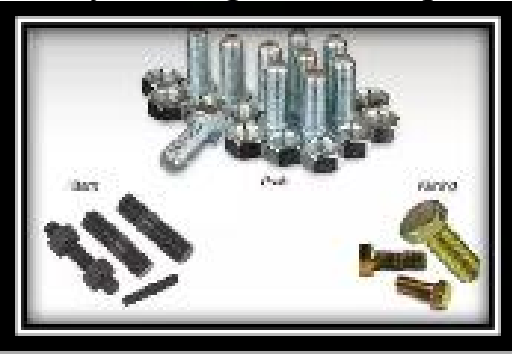

Gambar 10. Mor dan Baut

\section{Peralatan Pembuatan Mesin Pemotong Padi}

\section{Las listrik}

Digunakan untuk proses penyambungan logam dengan memanfaatkan tenaga listrik sebagai sumber panasnya untuk melelehkan atau mencairkan permukaan benda kerja dengan membangkitkan busur nyala listrik melalui elektroda.

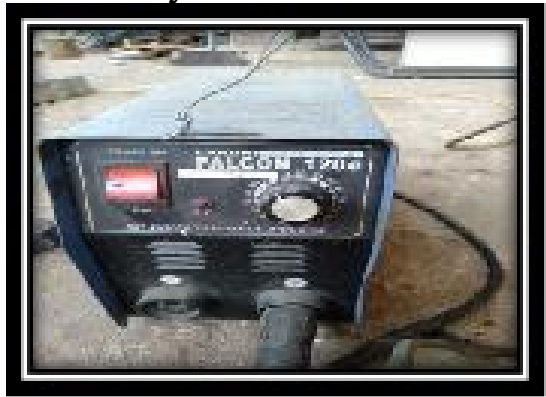

Gambar 11. Las Listrik

\section{Gerinda}

Merupakan mesin perkakas digunakan untuk mengasah/memotong atau menggerus benda kerja dengan tujuan untuk mendapatkan hasil potongan sesuai dengan rancangan. 


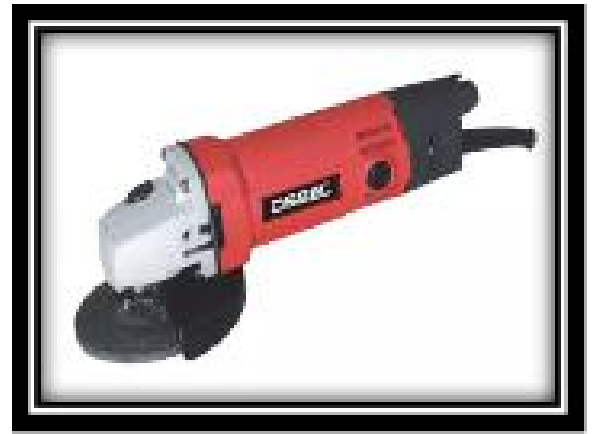

Gambar 12. Gerinda

\section{Mesin Bor}

Digunakan untuk melubangi benda kerja dengan ukuran tertentu. Prinsip kerja mesin bor dengan cara memutar mata pisau bor dengan kecepatan tertentu.

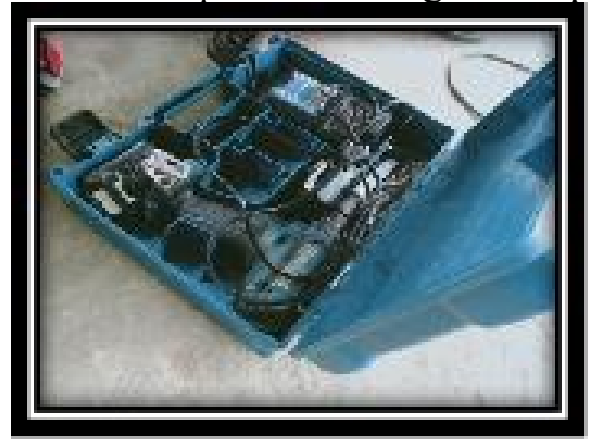

Gambar 13. Mesin Bor

\section{Alat Uji Lapangan}

\section{Digital Tachometer}

Tachometer merupakan alat instrument yang dirancang untuk mengukur kecepatan rotasi dari sebuah objek, seperti alat pengukur dalam sebuah mobil yang mengukur putaran per menit (RPM) dari poros engkol mesin. Tingkat ketelitian batas ukuran terkecil pada tachometer yaitu 0,01 1/min. Digital tachometer memberikan pembacaan numeric tepat dan akurat yang hasilnya ditampilkan pada layar LCD berupa angka.

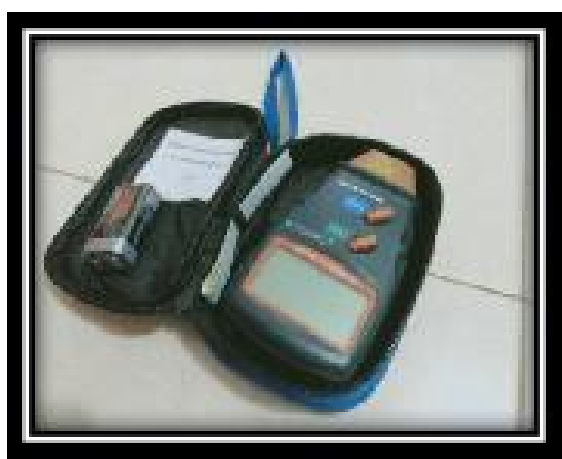

Gambar 14. Digital Tachometer

\section{Gelas Ukur}

Digunakan untuk mengukur volume bensin yang akan digunakan sebagai takaran jumlah bahan bakar yang terpakai. 


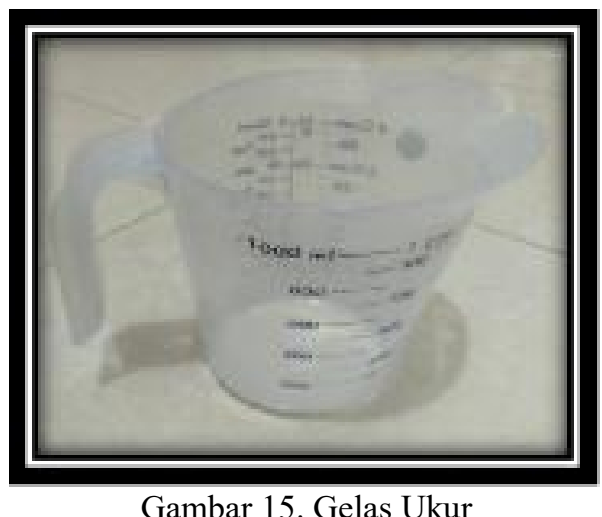

3. Meteran

Digunakan sebagai alat ukur jarak atau panjang. Dipakai saat membuat alat dan mengukur luasan lahan sawah.

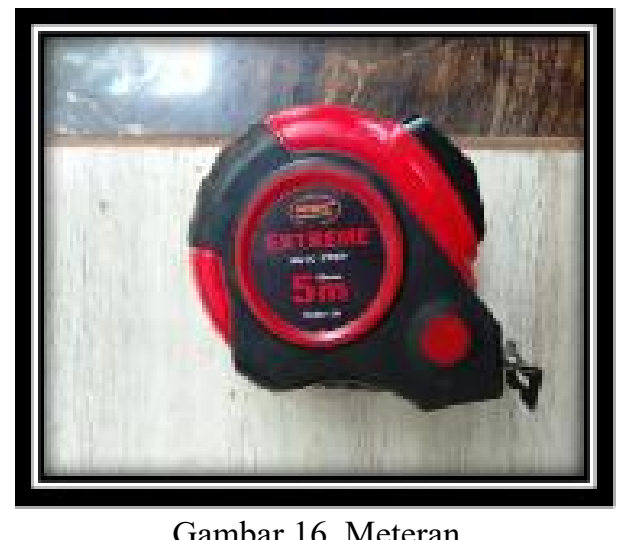

4. Busur

Digunakan untuk mengukur ukuran derajat konstruksi alat yang dibuat agar sesuai dengan gambar teknik.

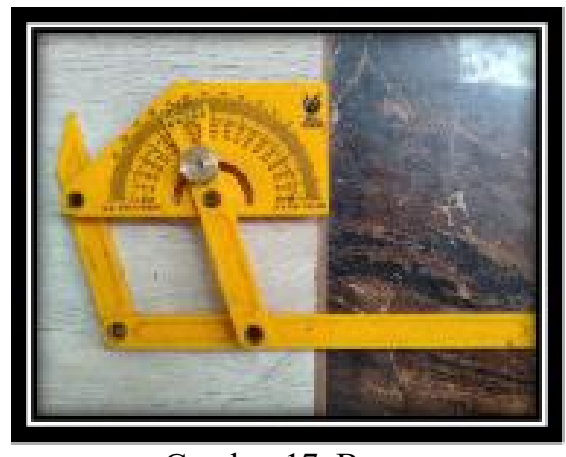

\section{Stopwatch}

Gambar 17. Busur

Digunakan sebagai alat untuk mengukur lamanya waktu yang diperlukan dalam melakukan pengujian mesin pemotong padi di lapangan. 


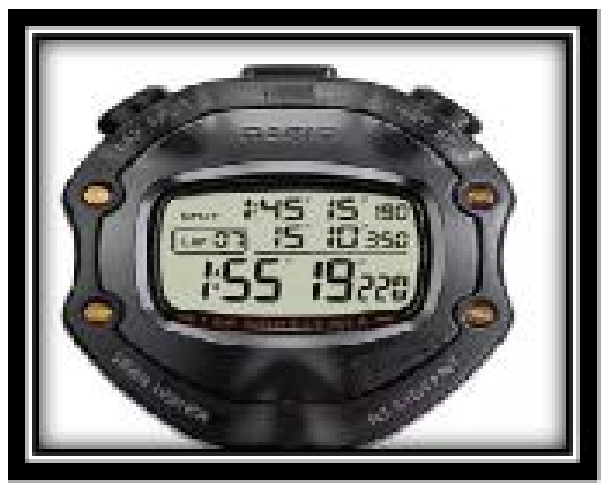

Gambar 18. Stopwatch

6. Neraca Pegas

Kelebihan menimbang beban dengan neraca pegas yaitu dalam sekali menimbang benda dapat diketahui massa dan berat benda sekaligus.

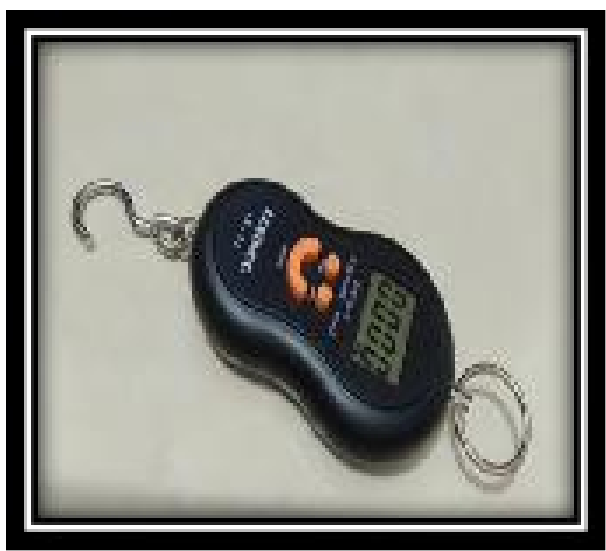

Gambar 19. Neraca Pegas

\section{HASIL DAN PEMBAHASAN}

\section{A. Detail Design Mesin Pemotong Padi Sederhana}

Hasil rancangan dari prototype mesin pemotong padi sederhana lebih detail akan dijelaskan secara rinci pada gambar 1 berikut ini.

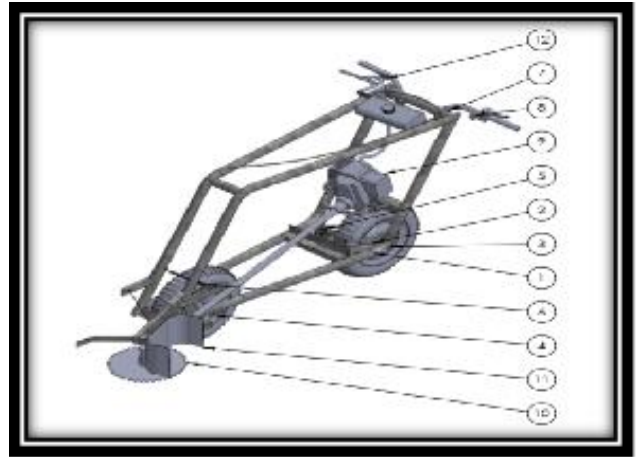

\section{Rangka Utama}

Gambar 20. 3D Assembly Mesin Pemotong Padi Sederhana

Perancangan dan Pembuatan Mesin Pemotong Padi Sederhana di Desa Pitalah Kabupaten Tanah Datar Oknovia Susanti dkk. Hal. 146-160 
Perancangan rangka utama di desain berdasarkan aspek Ergonomi dan data anthropometri. Tujuan yang dapat dicapai adalah alat ini berfungsi dengan efektif, aman dan nyaman berdasarkan pertimbangan ergonomi dalam proses perancangan produk maupun sistem kerja yang akan memerlukan interaksi manusia. Di samping itu dimensi rangka dipedomani berapa jarak tanam padi, ketinggian padi serta harus berdasarkan daerah maksimum dan optimum manusia mendorong alat.

Fungsi rangka harus mampu menempatkan dan menopang mesin, roda serta komponen-komponen yang ada pada mesin pemotong padi yang akan dibuat. Syarat yang harus dipenuhi dalam perancangan rangka yaitu sebaiknya material yang dipakai untuk rangka harus kuat dan kaku tapi ringan, rangka harus sesuai dengan geometri yang diinginkan sistem kemudi, karena membutuhkan tenaga manusia untuk mendorong alat maka rangka utama dilengkapi dengan stang agar lebih memudahkan dalam proses mendorong alat, kemudian rangka harus mampu menjaga roda tetap sejajar lurus antara depan dan belakang. Untuk sistem kemudi yang akan dirancang pada rangka ini menggunakan ban belakang berputar pada sumbu roda belakang yang dapat dibelokkan sedangkan untuk ban depan diposisikan berputar pada sumbu depan. Komponen pendukung lainnya yang terdapat pada rangka utama seperti tuas pelempar, spring pelempar, spring suspensi dan tuas rpm. Prinsip kerja dari pelempar padi adalah dengan cara menekan tuas pelempar tepat saat dilakukan pemotongan ketika mata pisau memotong batang padi maka pada saat itu pula tuas pelempar dilepaskan sehingga batang padi terlempar ke samping. komponen tambahan lainnya adalah penangkap yang digunakan untuk menangkap satu rumpun padi sebelum mengenai mata pisau potong.

Rangka utama dirancang dari besi galvanis dengan ukuran 1 inch. Pemilihan besi galvanis ini memiliki keunggulan dari segi ketahanan terhadap karat cukup tinggi karena dilapisi material seng dan memiliki topangan kuat untuk komponen lainnya serta mudah pada saat perancangan, dari segi harga lebih terjangkau.

\section{Mata Pisau Potong 40 T}

Pemilihan mata pisau $40 \mathrm{~T}$ berpedoman pada mesin mower karena telah teruji berdasarkan keefektifan saat penggunaan di lapangan dan hasil yang diterapkan pada saat pemotongan padi terpotong rapi dan batang padi tidak hancur saat terpotong.

Kriteria pemilihan mata pisau berdasarkan fungsi yang lebih mendukung saat diterapkan pada alat yang akan dibuat. Kendala kenapa tidak memakai mata pisau berbentuk persegi panjang yang banyak dipakai untuk memotong rumput, pengamatan kualitatif yang diperoleh ketika saat memotong rumput, objek rumput menjadi hancur dengan kualitas pemotongan yang tidak rapi jika diterapkan pada alat maka kekurangannya padi terpotong bertebangan yang dapat menyebabkan bulir padi bercecer disawah.

Pemakaian jumlah mata pisau, jumlah mata pisau yang dipakai hanya satu buah disesuaikan dengan dudukan pisau mesin yang hanya mampu dipasang satu bagian saja, di samping itu untuk mengutamakan safety jika pemakaian dua mata pisau dapat menyebabkan beban yang berat pada kinerja mesin, dan menimalisir terjadinya mata pisau terlepas saat mesin beroperasi.

Pisau pemotong menggunakan 1 bagian yaitu pisau pemotong diposisikan depan. Pisau pemotong memiliki diameter yaitu $255 \mathrm{~mm}$ dengan ketebalan mata pisau 2 $\mathrm{mm}$. Pisau pemotong merupakan standar bawaan pabrik. 


\section{Pelempar Padi}

Pelempar padi di rancang dengan konsep untuk memandu padi ke arah samping agar posisi padi yang terpotong tersusun ke arah padi yang belum terpotong dan tidak terinjak oleh ban. Keuntungan dalam perancangan part ini yaitu desain yang tidak rumit namun memberikan nilai alat menjadi maksimal untuk padi setelah tepotong dan dapat menata susunannya.

Komponen ini berguna untuk membantu mengarahkan padi ke arah samping setelah padi terpotong. Komponen ini di desain dengan material plat logam dengan tebal $2 \mathrm{~mm}$.

\section{Mesin Potong Rumput Yasui YSI-328}

Pemilihan dari mesin potong rumput Yasui YSI-328 berdasarkan prinsip kerja yang tidak rumit sehingga mudah diimplementasikan keperancangan alat, dimensi mesin yang kecil serta bobot yang ringan dapat menunjang pada kinerja alat saat mendorong menggunakan tenaga manusia, konsumsi bahan bakar yang hemat, rpm kecepatan pada mesin dapat diatur dengan mudah, perawatan mesin yang lebih simpel dan harga terjangkau.

Mesin potong rumput Yasui YSI-328 ini berguna untuk sebagai sumber tenaga untuk memutar mata pisau potong $40 \mathrm{~T}$ yang digunakan untuk proses pemotongan padi. Mesin dilengkapi dengan tuas rpm sehingga memudahkan untuk menaikkan dan menurunkan putaran mesin.

Spesifikasi dari mesin dapat dilihat sebagai berikut :

- Mesin

- Silinder

- Bahan Bakar

- Kapasitas Tangki

- Starter

- Sistem Ignisi
: 2 Tak 1.8 HP $7000 \mathrm{rpm}$

$: 30.5 \mathrm{cc}$

: Bensin campur oli 2 Tak (25:1)

: 1.2 liter

: Recoil

: Transistorized Electronic

\section{Roda}

Pemilihan roda disesuaikan dengan kondisi lapangan dan bentuk rancangan dimana berat dari keseluruhan alat akan ditopang oleh roda sehingga dibutuhkan roda yang kuat, diamater yang tidak terlalu besar agar memudahkan untuk bermanufer, luas penampang ban tidak boleh terlalu kecil jika kecil mudah terbenam di sawah yang kondisinya tidak kering. Jadi jenis roda yang mendukung adalah ban gerobak di samping telah banyak dipakai dan mudah untuk didapatkan.

Roda berfungi untuk membantu agar alat dapat berjalan di area sawah. Untuk roda sendiri memakai roda gerobak pasir merek arto, tipe ban hidup pakai ban dalam bahan karet dan untuk diameter $32 \mathrm{~cm}$.

\section{Analisa Performa}

\section{Kapasitas Kerja Mesin (KKM) ha/jam}

Kapasitas kerja mesin pemotong padi sederhana didapat dengan mengetahui berapa luas area sawah (ha) yang mampu diselesaikan terhadap waktu pengerjaan (jam). Data di lapangan diketahui jenis varietas padi yang ditanam adalah "Anak Daro" dengan jarak tanam bervariasi berkisar dalam rentang $25 \mathrm{~cm} \times 25 \mathrm{~cm}$ sampai $30 \mathrm{~cm} \times 30 \mathrm{~cm}$, ratarata tinggi tanaman $92,5 \mathrm{~cm}$ dan rata-rata jumlah anakan 19 batang dalam satu rumpun 
padi. Luas area yang dipatok pada setiap jarak lintasan adalah $2,75 \mathrm{~m}^{2}$ nilai tersebut diperoleh dari panjang lintasan di kali dengan rata-rata jarak tanam. Panjang lintasan diketahui $10 \mathrm{~m}$ sedangkan lebar rata-rata jarak tanam yang diambil 27,5 $\mathrm{cm}$ atau 0,275 m. Sehingga diperoleh luas area dalam lintasan secara matematis :

$$
\begin{aligned}
\text { Luas Area Lintasan } & =10 \mathrm{~m} \times 0,275 \mathrm{~m} \\
& =2,75 \mathrm{~m}^{2} \\
& =0,000275 \mathrm{ha}
\end{aligned}
$$

Grafik rata-rata hasil kapasitas kerja mesin pemotong padi sederhana dan kapasitas kerja sabit tradisional disajikan pada Gambar 20.

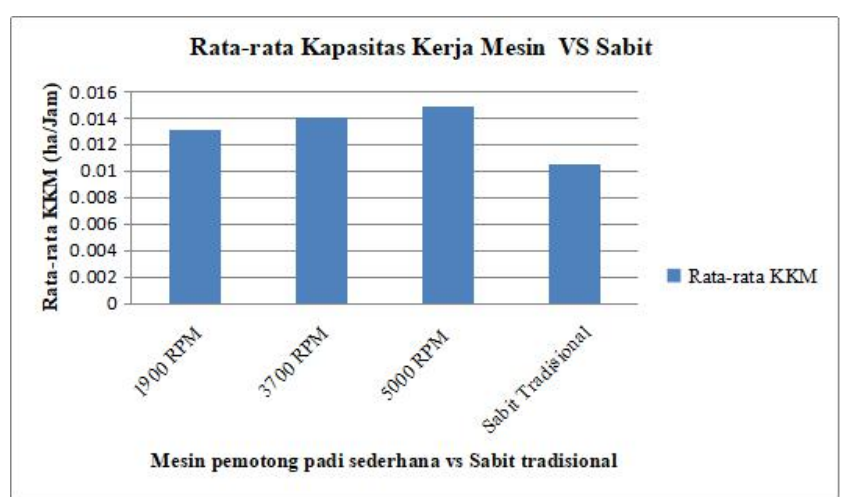

Gambar 20. Grafik Rata-Rata Kapasitas Kerja Mesin Pemotong Padi Sederhana VS Sabit Tradisional

Dari grafik diperoleh nilai rata-rata kapasitas kerja mesin pemotong padi sederhana saat percobaan adalah 0,0131 ha/jam, 0,0141 ha/jam, 0,0149 ha/jam pada masing-masing variasi rpm mesin yaitu $1900 \mathrm{rpm}, 3700 \mathrm{rpm}$ dan $5000 \mathrm{rpm}$. Sedangkan rata-rata kapasitas kerja menggunakan sabit tradisional adalah 0,0105 ha/jam. Dari percobaan dilihat variasi rpm sangat berpengaruh terhadap kapasitas kerja. Berdasarkan grafik dapat disimpulkan bahwa kapasitas kerja mesin pemotong padi sederhana lebih tinggi dibandingkan dengan sabit tradisional. Hal tersebut disebabkan karena pada saat memotong padi menggunakan mesin pemotong padi sederhana sumber tenaga yang berguna untuk memotong rumpun padi dilakukan oleh kerja mesin sehingga lebih mudah dan operator hanya sebagai pengendali alat, dari segi kenyamanan postur tubuh lebih rileks dibandingkan menggunakan sabit tradisional. Hal ini dikarenakan motor penggerak mesin pemotong padi sederhana lebih besar (1.8 hp) dibandingkan dengan menggunakan cara tradisional yang sepenuhnya mengandalkan tenaga manusia. Dilihat dari segi cara penggunaan sabit tradisional, dimana cara penggunaannya dilakukan dengan membungkukkan badan secara berulang-ulang dan hal tersebut berpengaruh terhadap kapasitas kerja saat pemotongan padi. Di samping itu terdapat beberapa faktor yang memengaruhi nilai kapasitas kerja pemotongan antara lain keterampilan operator, kondisi lahan, dan jarak tanam pada lahan tersebut.

Analisis pada grafik menunjukkan bahwa rpm berpengaruh terhadap kapasitas kerja mesin, hal ini dikarenakan semakin tinggi putaran mata pisau pemotong maka waktu yang dibutuhkan untuk memotong semakin cepat sehingga kapasitas kerja akan semakin tinggi.

Variasi rpm yang diuji coba menggunakan mesin pemotong padi sederhana menunjukkan hasil pemotongan rumpun padi yang berbeda berdasarkan dengan tingkat 
kualitas pemotongan. Hasil pemotongan yang kurang baik terdapat pada rpm rendah yaitu $1900 \mathrm{rpm}$, sedangkan pada rpm 3700 hasil pemotongannya sedikit lebih unggul dari rpm 1900 namun hasilnya kalah cepat menggunakan rpm yang tinggi yaitu 5000 rpm. Sehingga dapat disimpulkan rpm 5000 memberikan kualitas pemotongan yang sangat baik.

\section{Konsumsi Bahan Bakar (KBB)}

Konsumsi bahan bakar diperoleh dengan cara mengukur berapa banyak bensin yang dibutuhkan dalam melakukan percobaan pada masing-masing rpm terhadap luas sawah. Untuk ukuran sawah pengujian berukuran $20 \mathrm{~m}$ x $30 \mathrm{~m}$, sehingga luas sawah adalah $600 \mathrm{~m}^{2}$ atau 0,06 ha. Hasil pengukuran kebutuhan bahan bakar yang diperlukan untuk memotong padi disajikan dalam bentuk grafik pada Gambar 4.4. Dari grafik diketahui bahwa konsumsi bahan bakar yang habis pada variasi $1900 \mathrm{rpm}, 3700 \mathrm{rpm}$ dan $5000 \mathrm{rpm}$ masing masing adalah 15,3333 1/ha; 14 1/ha dan 12,6667 1/ha. Analisis pada grafik menunjukkan bahwa rpm berpengaruh terhadap konsumsi bahan bakar semakin tinggi rpm maka konsumsi bahan bakar lebih sedikit. Pada kecepatan rendah konsumsi bahan bakar lebih besar dikarenakan pada saat pemotongan batang padi tidak terpotong sempurna sehingga waktu yang dibutuhkan lebih lama. Maka perlakuan rpm berpengaruh terhadap bahan bakar.

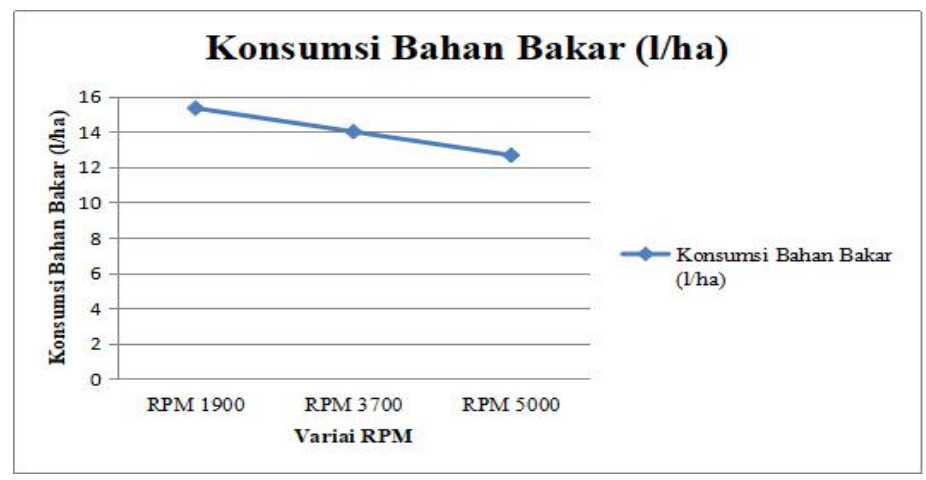

Gambar 21. Kebutuhan Bahan Bakar Menggunakan Mesin Pemotong Padi Sederhana

\section{KESIMPULAN DAN SARAN}

Dari kegiatan yang telah dilakukan diperoleh kesimpulan: 1) Nilai optimum rata-rata kapasitas kerja mesin pemotong padi sederhana berada pada putaran mesin $5000 \mathrm{rpm}$ dengan rata-rata kapasitas kerja yang diperoleh saat percobaan adalah 0,0149 ha/jam. Sedangkan nilai minimum rata-rata kapasitas kerja mesin pemotong padi sederhana adalah $0,0131 \mathrm{ha} / \mathrm{jam}$ pada $1900 \mathrm{rpm}$. Untuk rata-rata kapasitas kerja pemotongan menggunakan sabit tradisional adalah 0,0105 ha/jam. 2) Konsumsi bahan bakar yang paling banyak habis terpakai terdapat pada variasi $1900 \mathrm{rpm}$ yaitu 15,3333 1/ha, disebabkan rpm rendah berpengaruh terhadap hasil pemotongan kurang baik dan memakan waktu relatif lama sehingga berdampak pada boros konsumsi bahan bakar. Sadangkan konsumsi bahan bakar lebih kecil berada di $5000 \mathrm{rpm}$ yaitu 12,6667 1/ha. 3) Mesin pemotong padi sederhana dibandingkan dengan sabit tradisional memilki keunggulan dari segi kecepatan pemotongan, jumlah tenaga kerja dan tingkat kelelahan 
saat pemotongan padi. Untuk perbandingan tenaga mesin pemotong padi sederhana setara dengan 2 orang petani.

\section{UCAPAN TERIMA KASIH}

Terima kasih diucapkan kepada masyarakat Jorong Baru Kelurahan Pitalah, Kecamatan Batipuh Kabupaten Tanah Datar. yang telah memberikan kesempatan dalam melakukan pengujian alat pemotong padi sederhana di lahan sawah dan serah terima alat di Jorong Baru Kelurahan Pitalah Kecamatan Batipuh KabupatenTanah Datar.

\section{DAFTAR PUSTAKA}

Andra, G.S. 2018. Modifikasi Alat Tanam Jagung Tipe Putar (Rolling Planter) di Kabupaten Pasaman Barat.

Anisa, S. 2018. Unjuk Kerja Mesin Pemotong Padi (Paddy Mower) Pada Proses Pemanenan Padi (Oryza Sativa L.) di Lahan Basah.

Anisa, Siti, Siti Suharyatun, Oktafri, and Sandi Asmara. 2018. Performance of paddy mower on harvesting rice (Oryza sativa l.) in wet land. Teknik Pertanian Lampung 7(2):63-121.

Antoni, Sigit, Zulfah, and Tofik Hidayat. 2016. Perancangan Meja Konveyor Sebagai Media Pembelajaran Untuk Memepertimbangkan Faktor Antropometri di Laboratorium Analisa Perancagan Kerja Fakultas Teknik. 12(1):48-56.

Arum, Nanda Kusuma and Chusnan Muslikin. 2017. Mengenal Alat dan Mesin Pemanen Padi.

Giesecke. 2001. Gambar Teknik. $11^{\text {th }}$ ed. Erlangga, Jakarta.

Harnel and Buharman. 2011. Kajian tekniks dan ekonomis mesin penyiang (power weeder) padi di lahan sawah tadah hujan." Pengkajian Dan Pengembangan Teknologi Pertanian 14(1):1-10.

Harsokusoemo, H. D. 1999. Pengantar Perancangan Teknik. Direktorat Jenderal Pendidikan Tinggi, Departemen Pendidikan Nasional, Bandung.

Hayashi and Mandang. 1990. Pengantar Ilmu Ketenagaan Kerja di Bidang Pertanian. IPB, Bogor.

Iswari, Adhelina Rinta, Hani'ah, and Arief Laila Nugraha. 2016. "Analisis fluktuasi produksi padi akibat pengaruh kekeringan di Kabupaten Demak." Geodesi Undip 5(4): 23-42. 
Iswari, K. 2012. Kesiapan Teknologi Panen dan Pascapanen Padi dalam Menekan Kehilangan Hasil dan Meningkatkan Mutu Beras.31(2).

Noer, Melinda, Ira Wahyuni Syarfi, and Rafnel Azhari. 2019. Persiapan peremajaan kebun kelapa sawit oleh KUD Suka Maju dan KUD Bukit Jaya di Kabupaten Dharmasraya Provinsi Sumatera Barat. Buletin Ilmiah Nagari Membangun 2(3).

Nuryadin, I. 2017. Rancang Bangun Alat Pembelah Buah (Areca Catechu L.) Tipe Tang Pinang. Fakultas Teknologi Pertanian Universitas Andalas.

Shafirta, G. 2014. Rancang Bangun Alat Pemotong Telur Dadar Pada Proses Pembuatan Rendang Telur Tipe Manual Skala Industri Rumah Tangga.

Sutanto, Agus, Nota Effiandi, and Alfian Alfian. 2017. Rancangan teknologi tepat guna untuk pembuatan cakram pemutar turbin aliran silang skala bengkel. Warta Pengabdain Andalas, 24(2).

Teguh, Muhamad, Angga Saputra, Siti Suharyatun, Sandi Asmara, and Agus Haryanto. 2018. Performance test of paddy cutting machine type GLX 328-RH in some RPM on dry land." Teknik Pertanian Lampung 7(3):168-74.

Virmani, S. S. and Sharma H. L. 1998. Manual for Hybrid Rice Seed Production. IRRI Los Banos, Philippines.

Wanders, A. A. 1987. Pengukuran Energi Dalam Strategi Mekanisasi Pertanian. IPB.

Wright, P. H. 2002. Introduction To Engineering. Third. edited by J. Willey and Sons. New York. 